\title{
Entomological and functional role of floral strips in an organic apple orchard: Hymenopteran parasitoids as a case study
}

\author{
Hazem Dib · Gilles Libourel · François Warlop
}

Received: 2 September 2011 / Accepted: 9 February 2012/Published online: 18 February 2012

(C) Springer Science+Business Media B.V. 2012

\begin{abstract}
Habitat manipulation techniques improve the availability of resources required by natural enemies to increase their effectiveness. This study focused on the effects of floral strips on Hymenopteran parasitoid presence. The experiments were conducted during spring 2007 in one organic low-input apple orchard located in southeastern France. The density and the diversity of parasitic wasps collected from sown floral strips were higher than those from mown plants. The family of parasitic wasps of Braconidae was strongly dominant, followed by Mymaridae and Pteromalidae. By studying 26 flowering species, the greatest diversity and density of parasitic wasps were collected from Potentilla reptans, Achillea millefolium, Trifolium repens and Torilis arvensis. In terms of the early flowering plants, the most important results were observed in Euphorbia helioscopia, Senecio vulgaris and Veronica persica. To give an idea of the functional role of these plants, we studied the parasitic wasps of the diapausing larvae (cocoon) of codling moth Cydia pomonella. We recorded three emerged species: Ascogaster quadridentata, Pristomerus vulnerator and the hyperparasite Perilampus fulvicornis. However, none of these species have been observed on the 26 studied plants. Hence, this result may be suggesting that the studied plants do not have a functional role concerning these parasitoids. These studies may be advantageous for biological control programs in order to
\end{abstract}

H. Dib $(\bowtie)$

Department of Plant Protection, Faculty of Agriculture,

Biological Control Studies and Research Center,

University of Damascus, Damascus, Syria

e-mail: hazem.dib@avignon.inra.fr; hazem802005@yahoo.com

G. Libourel · F. Warlop

GRAB "Groupe de Recherche en Agriculture Biologique", Site

Agroparc, BP 1222, 84911 Avignon Cedex 9, France select flowering plant species attracting parasitic wasps specific to fruit pests.

Keywords Conservation biological control $\cdot$ Habitat manipulation · Codling moth $\cdot$ Cydia pomonella

\section{Introduction}

The biological control of herbivorous pests can be improved by habitat manipulation in order to favour natural enemies providing suitable microclimates, alternative preys and floral resources for adult natural enemies (Landis et al. 2000; Rebek et al. 2005). In particular, establishing floral vegetation can provide adult parasitic wasps with essential nutrients and energy, and may improve longevity, fecundity, flight ability and rates of parasitism (Jervis et al. 1993; Tooker and Hanks 2000).

Although the availability of flowering plant has important implications for conservation biological control, little is known of the specific associations between parasitic wasps and flowering plant species (Jervis et al. 1993). This host-plant fidelity could be used in biological control programs for selecting plant species that attract parasitoid species (Tooker and Hanks 2000).

In the context of moves to increase biodiversity and enhance ecosystem functioning in the agricultural matrix, we tried in this work to provide a test of whether floral strips, which increase resources for invertebrates in general also provide resources for natural enemies of pest species. The present study investigated the influence of floral strips on the abundance and the diversity of parasitic wasps (entomological role) in an apple organic orchard. To give an idea of the functional role of these strips, we studied the parasitic wasps of the diapausing larvae of codling moth 
Cydia pomonella (Lepidoptera: Tortricidae), a major worldwide pest of apple and pear (Mills 2005).

\section{Materials and methods}

Study orchard and floral strips

The studies were conducted during spring 2007 on an organic low-input apple orchard of 0.62 ha located near Avignon in south-eastern France $\left(43^{\circ} 56^{\prime} 55^{\prime \prime} \mathrm{N} 4^{\circ} 48^{\prime} 30^{\prime \prime} \mathrm{E}\right)$. It was planted in 2001 with 212 trees in 9 rows. The only insecticides applied were granulosis virus and Bacillus thuringiensis to control codling moth and others Lepidoptera. During the sampling period, no horticultural management practices were carried out in the orchards except for mowing of spontaneous herbaceous strips between tree rows.

In autumn 2003, four floral strips of $1 \mathrm{~m}$ width and 100-150 m length each were sown. Three strips in the middle between two apple rows and another one on the border of the orchard.

\section{Sampling method and statistical analysis}

The parasitic wasps were collected into tissue bags using aspirators. We studied the importance of 26 flowering species divided into 12 families (Table 1) regarding their attraction to parasitic wasps. Flowering plant species were selected for sampling according to the following criteria: (1) presence of flowers during the observation period and (2) having a minimum of 25 flowers in the observation area. One aspiration bag was used per plant species (three replicates per species and $5 \mathrm{~s}$ of aspiration per plant replicate). We concurrently sampled the mown plants (without flowers) as control. Each plant species was evaluated between three and seven times in 15 sampling series of aspiration between 19 March and 31 May 2007. In the laboratory, the parasitoid wasps were isolated and determined to family using the key of Delvare and Aberlenc (1989). The mean number of parasitoid wasps computed on each flowering species were compared with the Mann-Whitney $U$ test using XLSTAT Version 2009/05/01.

Study the parasitic wasps of the codling moth cocoons

212 corrugated cardboard bands (60 mm diameter) were wrapped around the trunks of apple trees in June 2006 ( 1 band/tree). They were collected in October 2006 and in March 2007. In laboratory: 294 larvae were recovered. Each of them was put in a tube and observed until adult emergence (adult of codling moth or parasitoid wasp). The emerging parasitoid wasps were determined until species level using the key of Athanassov et al. (1997).

\section{Results and discussion}

Hymenopteran parasitoid families

A total of 1,469 parasitic wasps divided into 22 families were collected from the 26 studied flowering species and the mown plants (control). The majority of Hymenopteran parasitoids collected belonged to the Braconidae family with 423 individuals (28.8\% of all parasitoid wasps collected), followed by Mymaridae (22.8\%) and Pteromalidae $(8.7 \%)$. These families were found on all the flowering species and control plants on all the observation dates. Each of the remaining families comprised $6.5 \%$ or less of the total parasitic wasps (Diapriidae, Eulophidae, Mymarommatidae, Encyrtidae, Cynipidae, Scelionidae, Ichneumonidae, Aphelinidae, Megaspilidae, Platygasteridae, Eurytomidae, Ceraphronidae, Eucoilidae, Tetracampidae, Charipidae, Figitidae, Serphidae, Trichogrammatidae and Evanidae).

Braconids, which parasitize a wide range of hosts including Hemiptera, Lepidoptera, Hymenoptera, Diptera and Coleoptera (Debach and Rosen 1991), are the most widespread family in Europe (more of 2,000 species) (Belokobylsckji and Tobias 2000). They are considered almost entirely beneficial and many species have been introduced or conserved in biological control programs (Tooker and Hanks 2000).

\section{Entomological role of floral strips}

This study demonstrates that the density and the diversity of parasitic wasps collected from sown floral strips were higher than those from mown plants (Table 1), as found by similar studies (Jervis et al. 1993; Landis et al. 2000; Rebek et al. 2005). Floral strips are attractive for adult parasitic wasps which often visit flowers to feed on floral resources: pollen and/or nectar (Landis et al. 2000; Rebek et al. 2005).

Among the 26 flowering species studied (Table 1), the greatest diversity and density of wasps was collected from Cinquefoil (Potentilla reptans), Yarrow (Achillea millefolium), White clover (Trifolium repens) and Hedge-parsley (Torilis arvensis). In contrast, the lowest results were recorded on Melilot (Melilotus officinalis), Mallow (Malva sylvestris) and Salsify (Tragopogon pratensis).

In terms of the early flowering plants (Table 1), the most important were Spurge (Euphorbia helioscopia), Groundsel (Senecio vulgaris) and Field-speedwell (Veronica persica). Establishing these species, which start to flower early in the season in the orchards, may promote the early establishment of natural enemies which may control early arrive pest species, e.g., the rosy apple aphid, Dysaphis plantaginea (Hemiptera: Aphididae) (Wyss 1995; Dib et al. 2010). 
Table 1 Mean (SE) diversity and density of parasitic wasps per flowering species in the apple orchard
Different letters indicate significant differences at the $5 \%$ significance level

$n$ number of assessments, * early flowering species

\begin{tabular}{|c|c|c|c|c|}
\hline Family of plant & Latin name & Diversity & Density & $n$ \\
\hline Apiaceae & Torilis arvensis & $8.67(1.71) \mathrm{a}$ & $4.44(1.31) b$ & 3 \\
\hline \multirow[t]{9}{*}{ Asteraceae } & Achillea millefolium & $7.00(1.56) \mathrm{ab}$ & 9.55 (3.34) a & 3 \\
\hline & Carduus tenuiflorus & $6.40(0.41) b$ & $3.53(0.31) \mathrm{c}$ & 5 \\
\hline & Coreopsis tinctoria & $6.67(0.68) b$ & $3.44(0.69) \mathrm{c}$ & 3 \\
\hline & Crepis sancta* & $3.34(0.36) \mathrm{c}$ & $2.28(0.40) \mathrm{c}$ & 7 \\
\hline & Crepis vesicaria & $4.50(0.29) \mathrm{c}$ & $2.66(0.41) \mathrm{c}$ & 4 \\
\hline & Senecio vulgaris* & $4.14(0.89) \mathrm{c}$ & $3.57(1.00) \mathrm{c}$ & 7 \\
\hline & Sonchus oleraceus & $3.60(0.69) \mathrm{c}$ & $2.53(0.92) \mathrm{c}$ & 5 \\
\hline & Taraxacum officinale * & $3.71(0.55) \mathrm{c}$ & $2.43(0.39) \mathrm{c}$ & 7 \\
\hline & Tragopogon pratensis* & $1.57(0.42) \mathrm{d}$ & $1.14(0.46) \mathrm{d}$ & 7 \\
\hline Boraginaceae & Borago officinalis & $2.71(0.51) \mathrm{d}$ & $2.95(1.18) \mathrm{c}$ & 7 \\
\hline \multirow[t]{2}{*}{ Brassicaceae } & Capsella bursa-pastoris* & $2.50(0.29) \mathrm{d}$ & $1.83(0.32) \mathrm{cd}$ & 4 \\
\hline & Cardaria draba & $5.00(0.72) \mathrm{c}$ & $4.61(0.52) \mathrm{b}$ & 6 \\
\hline Euphorbiaceae & Euphorbia helioscopia* & $4.43(0.90) \mathrm{c}$ & $3.95(1.01) \mathrm{c}$ & 7 \\
\hline \multirow[t]{3}{*}{ Fabaceae } & Melilotus officinalis & $2.33(1.36) \mathrm{d}$ & $1.11(0.79) \mathrm{d}$ & 3 \\
\hline & Trifolium repens & $8.00(1.02) \mathrm{a}$ & $7.11(2.65) \mathrm{a}$ & 3 \\
\hline & Vicia sativa & $4.83(0.85) \mathrm{c}$ & $4.16(1.01) b c$ & 6 \\
\hline Malvaceae & Malva sylvestris & $2.00(0.59) \mathrm{d}$ & $1.11(0.41) \mathrm{d}$ & 3 \\
\hline Plantaginaceae & Plantago lanceolata & $4.60(0.83) \mathrm{c}$ & $2.80(0.66) \mathrm{c}$ & 5 \\
\hline \multirow[t]{3}{*}{ Poaceae } & Bromus catharticus & $5.67(0.90) \mathrm{c}$ & $3.66(0.85) \mathrm{c}$ & 3 \\
\hline & Bromus sterilis & $4.17(0.73) \mathrm{c}$ & $3.16(0.82) \mathrm{c}$ & 6 \\
\hline & Poa trivialis & $3.50(0.42) \mathrm{c}$ & $2.22(0.40) \mathrm{c}$ & 6 \\
\hline \multirow[t]{2}{*}{ Rosaceae } & Potentilla reptans & $9.40(1.27) \mathrm{a}$ & $17.00(5.71) \mathrm{a}$ & 5 \\
\hline & Sanguisorba minor & $4.40(0.69) \mathrm{c}$ & $3.00(0.60) \mathrm{c}$ & 5 \\
\hline Rubiaceae & Galium aparine & $6.33(1.48) b c$ & $5.33(1.60) \mathrm{ab}$ & 3 \\
\hline Scrophulariaceae & Veronica persica* & $4.00(1.00) \mathrm{c}$ & $3.33(1.08) \mathrm{c}$ & 4 \\
\hline Control & Mown plants & $1.64(0.20) \mathrm{d}$ & $0.66(0.09) \mathrm{d}$ & 11 \\
\hline
\end{tabular}

with few alternative resources available (Cortesero et al. 2000).

Closer examination of the aspiration results reveals that most of parasitic wasps were only collected from a small number of flowering species, suggesting that many Hymenopteran parasitoids are oligophagous. This host plant fidelity could be useful for biological control programs in selecting plant species that attract parasitoid species (Tooker and Hanks 2000).

Functional role of floral strips (parasitism of the codling moth cocoon)

The importance of this study is due to fact that the codling moth population growth is most vulnerable to additional mortality at the fifth instar or cocoon stage in its life cycle, and thus that parasitoids attacking these stages might be more effective in the biological control of this pest than parasitoids attacking other life stages (Mills 2005).

A total of 23 Hymenopteran parasitoids emerged between 10 April and 5 June 2007 from 294 larvae. Three emerged species were recorded; two primary parasitoids available compared to lab studies or simplified field studies 
Ascogaster quadridentata (Braconidae) (60.9\% of all wasp species recorded) and Pristomerus vulnerator (Ichneumonidae) (8.7\%), and a hyperparasitoid Perilampus fulvicornis (Perilampidae) $(30.4 \%)$. We remarked that A. quadridentata emerged first then $P$. vulnerator and finally $P$. fulvicornis which usually develops in the primary larval parasitoids and preferably in A. quadridentata (Espelie and Brown 1990). These parasitoid assemblages and their emergence chronology are similar to those reported previously (Espelie and Brown 1990; Mills 2005).

None of these emerged species were observed on the 26 studied plants or mown plants (control). Hence, this result may be suggesting that the studied plants do not have a functional role concerning these parasitoids.

The parasitism rate was generally low (7.82\%) and are in disagreement with the findings of Mills (2005) who has cited that the highest rates of parasitism recorded in Europe (10.3-42.6\%) for A. quadridentata and (27.9-32.4\%) for $P$. vulnerator. It is possible that (1) the young age of the orchard and so the low populations of $C$. pomonella have not yet allowed establishing a parasitic community sufficiently effective and/or (2) the treatments with biological pesticides have had negative effects on the Lepidoptera populations in general and on codling moth ones in particular and thus affected the parasitism rate.

In conclusion, these findings support the idea that floral resource availability in orchards may support and improve the efficiency of parasitoids as biological control agents. This is in addition to their previously demonstrated role in increasing opportunities for pollinator species (Carreck and Williams 2002) and general biodiversity (Landis et al. 2000). However, their use in supporting natural enemies requires a judicious selection of flowering species to attract parasitoids specific to pests. Thus, it would appear that the functional role of flowering plants in providing ecosystem services needs to be addressed in further studies.

\section{References}

Athanassov A, Charmillot P-J, Jeanneret Ph, Renard D (1997) Les parasitoïdes des larves et des chrysalides du carpocapse Cydia pomonella L. Revue suisse Vitic Arboric Hortic 29:99-106
Belokobylsckji SA, Tobias VI (2000) Key to the insects of Russian Far East (Neuropteroidae, Mecoptera, Hymenoptera). Dal'nauka, Vladivostok 4

Carreck NL, Williams IH (2002) Food for insect pollinators on farmland: insect visits to flowers of annual seed mixtures. J Insect Conserv 6:13-23

Cortesero AM, Stapel JO, Lewis WJ (2000) Understanding and manipulating plant attributes to enhance biological control. Biol Control 17:35-49

Debach P, Rosen D (1991) Biological control by natural enemies, 2nd edn. Cambridge University Press, Cambridge

Delvare G, Aberlenc H-P (1989) Les insectes d'Afrique et d'Amérique tropicale: clés pour la reconnaissance des familles. CIRAD, Montpellier

Dib H, Simon S, Sauphanor B, Capowiez Y (2010) The role of natural enemies on the population dynamics of the rosy apple aphid, Dysaphis plantaginea Passerini (Hemiptera: Aphididae) in organic apple orchards in south-eastern France. Biol Control 55:97-109

Espelie KE, Brown JJ (1990) Cuticular hydrocarbons of species which interact on four trophic levels: apple, Malus pumila Mill.; codling moth, Cydia pomonella L.; a Hymenopteran parasitoid, Ascogaster quadridentata Wesmael; and a hyperparasite, Perilampus fulvicornis Ashmead. Comp Biochem Physiol B Comp Biochem 95:131-136

Jervis MA, Kidd NAC, Fitton MG, Huddleston T, Dawah HA (1993) Flower-visiting by Hymenopteran parasitoids. J Nat Hist 27:67-105

Landis DA, Wratten SD, Gurr GM (2000) Habitat management to conserve natural enemies of arthropod pests in agriculture. Annu Rev Entomol 45:175-201

Mills NJ (2005) Selecting effective parasitoids for biological control introductions: codling moth as a case study. Biol Control 34:274-282

Patt JM, Hamilton GC, Lashomb JH (1997) Foraging success of parasitoid wasps on flowers: the interplay of insect morphology, floral architecture and searching behaviour. Entomol Exp Appl 83:21-30

Rebek EJ, Sadof CS, Hanks LM (2005) Manipulating the abundance of natural enemies in ornamental landscapes with floral resource plants. Biol Control 33:203-216

Tooker JF, Hanks LM (2000) Flowering plant hosts of adult Hymenopteran parasitoids of Central Illinois. Ann Entomol Soc Am 93:580-588

Wäckers FL (1994) The effect of food deprivation on the innate visual and olfactory preferences in the parasitoid Cotesia rubecula. J Insect Physiol 40:641-649

Wyss E (1995) The effects of weed strips on aphids and aphidophagous predators in an apple orchard. Entomol Exp Appl 75:43-49 